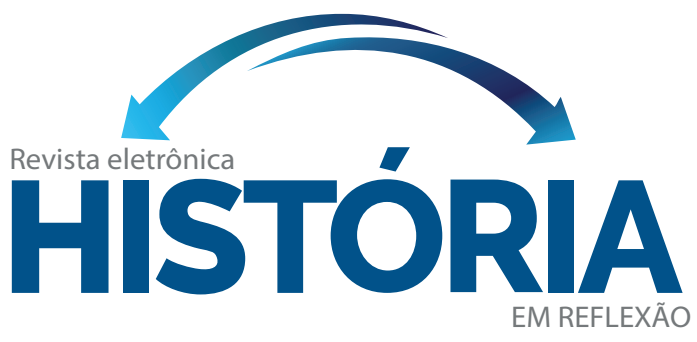

PPGH - Programa de Pós-Graduação em História

UFGD - Universidade Federal da Grande Dourados

\title{
AS RELAÇÕES DE GÊNERO NA EDUCAÇÃO FÍSICA ESCOLAR: UM ESTUDO DE REVISÃO BIBLIOGRÁFICA
}

ISSN: 1981-2434

Dourados - MS - Brasil

\author{
THE GENDER RELATIONSHIPS IN \\ SCHOOL PHYSICAL EDUCATION: A \\ BIBLIOGRAFIC REVIEW STUDY
}

JULIANA SOARES DA SILVA*

\begin{abstract}
RESUMO
Com a perspectiva de uma Educação Física escolar preocupada com a formação integral dos alunos e sobre a oportunidade de vivências múltiplas, sem preconceitos e com liberdade, faz-se uma reflexão acerca de oportunidades para meninos e meninas no contexto escolar. Essa reflexão torna-se necessária para compreendermos que reforços de estereótipos de masculino e feminino devem ser rompidos, logo que as aulas de Educação Física são momentos de contato, troca de experiências e de formação em todas as instâncias do ser humano. Uma aprendizagem significativa sem discriminação deve estar dentro da preocupação tanto de alunos como de professores. Portanto, o presente estudo visa analisar as relações de gênero na Educação Física escolar. Trata-se de uma pesquisa de revisão bibliográfica que utilizou livros e artigos de duas bases de dados (Scielo e Google Acadêmico). Os resultados a partir de análise do referencial teórico indicam que a Educação Física escolar é marcada pelo fator biológico que reforça estereótipos de gênero, que as relações entre gênero são marcadas pela exclusão do gênero feminino nas aulas e que o fator biológico é o principal citado quando se trata da divisão das turmas por gênero.
\end{abstract}

PALAVRAS CHAVE: Gênero. Aprendizagem. Educação Física.

\section{ABSTRACT}

With the perspective of school Physical Education concerned with the integral training of students and the opportunity for multiple experiences, without prejudice and freedom, a reflection is made about opportunities for boys and girls in the school context. This reflection becomes necessary to understand that reinforcement of male and female stereotypes must be broken, as soon as Physical Education classes are moments of contact, exchange of experiences and training in all instances of the human being. Meaningful learning without discrimination should be a concern for both students and teachers. Therefore, this study aims to analyze gender relations in school Physical Education. This is a bibliographic review research in which books and articles from two databases (Scielo and Google Scholar) were used. The results from the analysis of the theoretical framework indicate that school Physical Education is marked by the biological factor that reinforces gender stereotypes, that the relationship between gender is quite marked by the exclusion of the female gender in classes and that the biological factor is the main one mentioned when it comes to dividing classes by gender.

KEYWORDS: Gender. Learning. Physical Education.

\footnotetext{
* Graduação em Licenciatura em Educação Física pela Faculdade La Salle de Manaus. Pós-graduada em Neuropsicopedagogia e Pós-graduada em Treinamento Desportivo pela Uniasselvi de Palhoça. Formação Técnica de Vôlei de Praia (Nível 2) pela Confederação Brasileira de Voleibol. Professora de Educação Física do quadro efetivo - Secretaria Municipal de Educação e Cultura de Manaus e Secretaria de Estado de Educação e Qualidade do Ensino. E-mail: juliana.ss_12@hotmail.com
} 
Introdução

A Educação Física no Brasil é marcada por uma história de exclusão da mulher, pois era tida como um elemento para forjar indivíduos fortes e saudáveis, associando-a com a saúde corporal, que teve também a influência de médicos (Higienismo e Eugenia). Por suas raízes militaristas era uma prática exclusivamente masculina.

Conforme Castellani Filho (2016), a Educação Física ao ser incluída nas escolas passou por grande resistência, pois estava vinculada ao trabalho manual, o que era repudiado pela ética colonial, logo que assistiam aos filhos da elite. Porém em relação ao gênero, a Ginástica nas escolas era menos repudiada por pais de meninos, em vista que a mesma era oriunda das instituições militares, mas comparando-se ao sexo feminino a contrariedade foi histérica e muitas meninas foram proibidas de participar das aulas por seus pais.

Nesse momento (século XX), Castellani Filho (2016) afirma que as diferenças nos estereótipos de masculino e feminino eram cada vez mais evidentes. A sociedade tinha uma concepção de que homens e mulheres assumissem papéis distintos e a Ginástica para ambos os sexos proposta nas escolas primárias corroborou com essa ideia. As atividades propostas deveriam contemplar as necessidades femininas, tanto no que diz respeito a harmonia plástica, quanto às exigências da maternidade futura, além de jogos e esportes menos violentos e todas as atividades físicas compatíveis com a "delicadeza" feminina.

A imagem da mulher era vinculada ao seu corpo e à concepção. Um corpo tido como natural, reforçando uma ideia de fragilidade, passividade e doçura, o que serviu como amparo do controle do comportamento feminino, tendo como base suas características biológicas. Serviu para reforçar a ideia de superioridade masculina. A mulher deveria ter suas características femininas preservadas e as práticas físicas associadas à uma maternidade sadia, benéficas para si e para nação.

Devide et al. (2001) afirma que somente alguns anos depois surgem os questionamentos a respeito das práticas físicas relacionadas ao corpo feminino seguindo estudos no campo da Antropologia, Sociologia, História, Literatura, junto com a turbulenta situação política entre os anos de 1970 e 1980 decorrente do movimento feminista. A Educação Física brasileira então passou a refletir a temática de gênero, negando o argumento biologicista que se tornou justificativa para a exclusão de mulheres na Educação Física e no desporto.

No século em que vivemos há uma movimentação e exigência por profissionais que reestruturem e vinculem educação e humanização e assumam o papel de formadores de cidadãos. A Lei de Diretrizes e Bases da Educação Nacional (Brasil, 1996) traz consigo a ideia de uma escola comprometida com a formação da cidadania e com a rejeição à exclusão que é reforçada pelas Diretrizes Curriculares do Ensino Fundamental (Brasil, CNE 1998), que adotam princípios como a igualdade, a garantia de direitos e deveres e a ética e identidade. 
Os Parâmetros Curriculares Nacionais servem como apoio para a construção de projetos educativos para que a escola busque a inclusão. Nos dois livros - de $1^{\mathrm{a}}$ a $4^{\mathrm{a}}$ série (BRASIL, 1997) e de $5^{\mathrm{a}}$ a $8^{\mathrm{a}}$ série (BRASIL, 1998) - há indicações de que as aulas de educação física aconteçam de forma mista. Afirma-se que as aulas mistas podem proporcionar que meninos e meninas convivam, se conheçam, se descubram e aprendam a ser tolerantes. Além do mais aprendam a não construir estereótipos e relações sociais autoritárias.

Apesar de bases teóricas e pedagógicas sugerirem as mistas, Dornelles (2007) afirma que o gênero é levado em consideração na hora da definição dos conteúdos, procedimentos e práticas na disciplina de Educação Física. Por seu currículo ainda ser muito esportivo, algumas modalidades com características que envolvam maior contato físico, dificultam o trabalho misto, pois há uma distinção de corpos diferenciados pelo grau de competitividade, movimentação e interesse a elas relacionadas.

Segundo Brito e Santos (2013) a inclusão no contexto educacional é um dos maiores desafios atuais, onde uma educação de qualidade deve contemplar o respeito às diferenças em etnia, raça, gênero, orientação sexual e configura uma das grandes buscas do nosso século. Tal contexto, muitas vezes é apenas direcionado ao que se refere a pessoas com necessidades educativas especiais, mas seu significado é bem mais amplo e deve ser compreendido como um processo, assegurando princípios democráticos de participação social plena em todas as esferas da vida humana.

O ambiente escolar é um meio de formação do indivíduo e de sua cultura corporal do movimento, independentemente de suas características individuais, os conteúdos devem ser proporcionados de forma igualitária para todos. Portanto, objetivo geral da pesquisa é: Analisar as relações de gênero na Educação Física escolar.

Como objetivos específicos da pesquisa foram traçados os seguintes: descrever a evolução histórica da Educação Física escolar. Descrever as relações de gênero no contexto escolar. Identificar fatores que levam a divisão ou não da turma.

\section{Método}

Para realização desse estudo utilizou-se como metodologia a revisão bibliográfica, baseada na literatura especializada através da pesquisa de livros e artigos científicos disponíveis em base de dados especializadas.

As buscas de dados em livros foram feitas na biblioteca da Faculdade La Salle (Manaus) e os artigos científicos foram pesquisados da base de dados do Scielo e Google Acadêmico. Para as buscas foram utilizados como palavras-chave: Aprendizagem e Gênero, Gêneros na Educação Física escolar, Aulas Mista/Separadas por Gênero, Gênero na Seleção de Conteúdo na Educação Física. Foram selecionados artigos escritos em português e espanhol. 


\section{Evolução histórica da Educação Física escolar no Brasil}

Para entendimento do cenário atual é necessária uma reflexão sobre o desenvolvimento da Educação Física ao longo dos anos e suas principais influências que caracterizam essa componente curricular, que segundo Merida (2010) a Educação Física Escolar está amparada legalmente desde a Reforma Couto Ferraz de 1851 (Império) até a LDB atual (Lei 9394/96).

A Educação Física no Brasil surge a partir de uma visão europeia, com características higienistas e utilitárias. Porém não havia políticas de Estado que incentivassem a prática. Ela começa no Brasil quase de maneira acidental e o primeiro colégio público brasileiro a adotá-la como prática segundo Cunha Júnior (2003 apud JÚNIOR; SIMÕES, 2011), foi o Colégio Imperial de Pedro Segundo em 1841.

Afirma Castellani Filho (2016) que a introdução da Educação Física na escola se deu a partir de concepções higienistas pautadas por conotações de cunho eugênico. Porém levar a Educação Física para dentro das escolas não era visto com bons olhos, a considerar o pensamento da época. Entretanto, relacionado ao sexo masculino, as contrariedades eram mínimas, pois o que incomodava mesmo era o fato de que meninas pudessem praticar atividades físicas na escola.

Apesar de haver interesse do Governo em implementar a Educação Física nas escolas, havia muitos obstáculos para a implementação. Um deles era a resistência da elite brasileira, visto que as tarefas físicas estavam associadas a trabalhos manuais. Naquela época os trabalhos manuais eram tidos como de menor relevância, o importante era valorizar o intelectual.

Em 1874 Josino do Nascimento da Silva afirma em seu relatório que o fato fora tratado com "repugnância" pela opinião pública no que diz respeito às aulas de Ginástica, principalmente tratando-se da prática feminina. Foi preciso suspender as execuções, ainda que muitos pais tenham proibido suas filhas de participar de exercícios ginásticos.

Como elucida Castellani Filho (2016) apesar da resistência em tornar a Educação Física como obrigatória, armou-se de grande relevância o Parecer de Rui Barbosa no Projeto de número 224 em 1882, chamado "Reforma do Ensino Primário e várias instituições complementares da Instrução Pública”, onde tornou a Ginástica como disciplina de estudo, assim como os professores de Ginástica equipararam-se à autoridade dos demais professores de outras disciplinas.

Segundo Júnior e Simões (2011) Ruy Barbosa se mostrou um grande entusiasta da Educação Física, calcado pelas ideias higienistas. Porém sua concepção de democratização da prática só acontece no século XX. O Parecer de Rui Barbosa é umas das fontes mais citadas na história da Educação Física no Brasil, que mostra as características higienistas da época, levando em conta a construção de valores morais através do corpo. 
As relações de gênero na educação física escolar: um estudo de revisão bibliográfica

Soares (2012) afirma que o Parecer de Rui Barbosa buscava inserir de forma essencial a Ginástica em todas as escolas de ensino normal além de estender a obrigatoriedade da mesma para ambos os gêneros (masculino e feminino), logo que as meninas não tinham obrigatoriedade em fazê-la.

Apesar de grande relevância o Parecer de Rui Barbosa reforçava ainda mais estereótipos de gênero. Quando foi proposto a extensão da Ginástica para ambos os sexos nas escolas de todos os níveis, ficou bem claro o objetivo e as necessidades que se buscava nos ensinos das Ginásticas para mulheres: a harmonia em suas formas físicas e as exigências para uma maternidade futura.

Castellani Filho (2016) afirma que a mulher por sua natureza passiva deveria ser doce, fraca, maternal, sedutora e talvez pouco inteligente. As ideias da determinação biológica influenciaram também conceitos genéricos das atitudes femininas, servindo para controlar o comportamento feminino e de amparo à ideia dominante de superioridade do sexo masculino. Distanciado qualquer pensamento que relacionasse essa superioridade a determinantes socioculturais, mas sim biofisiológicos.

Cury e Bastos (2015) afirmam que o cenário político no Brasil nessa mesma época é marcado pela tentativa de inserção das mulheres. Em 1932 durante a Revolução Constitucionalista as mulheres obtiveram pela primeira vez permissão de votar, ocasionando um avanço na participação feminina efetiva na política do país. Em contraposição, no ano de 1941 o DECRETO-LEI Nº 3199 (1941) surge, porém com restrições à prática feminina no esporte.

Esse Decreto foi responsável por reforçar padrões da imagem da mulher na legislação da Educação Física e do Esporte. O DECRETO-LEI № 3199 de 14/04/41 no Art. 54 afirma que as mulheres não seriam permitidas de praticar desportos que sejam incompatíveis com a sua natureza. Ainda é afirmado através de instruções do Conselho Nacional de Desportos que a prática de esportes como lutas, futebol, futebol de salão, futebol de praia, polo aquático, polo, rugby, halterofilismo e baseball não era permitida.

Diversos aspectos quanto ao preconceito e discriminação contra as mulheres surgem nessa época e é somente em 1979 que essa situação é contornada, quando por intermédio de uma revogação há a suspensão as restrições do DECRETO-LEI N 3199.

Um fato chave e que deu abertura para discussões sobre a mulher nas práticas físicas, foi quando Joaquim Mamede, presidente da Confederação Brasileira de Judô inscreveu quatro atletas junto ao CND (Conselho Nacional de Desportos) com nomes masculinos para poder conseguir passagens a elas, para que pudessem disputar o Campeonato Sul-americano de Montevidéu em 1979. O grande detalhe é que nessa época a luta era proibida para mulheres.

Segundo Brasil (1997) o movimento escola-novista, evidenciou a importância da Educação Física na formação integral do indivíduo, o que ocasionou grandes discussões acerca dos métodos e práticas relacionados ao ensino da Educação Física. 
As relações de gênero na educação física escolar: um estudo de revisão bibliográfica

Soares (2012) afirma que a Educação Física no período Brasil república dividese basicamente em duas partes que são: 1890 que remete a primeira parte e até a Revolução de 1930, quando Getúlio Vargas foi empossado; a segunda parte configura o período após a Revolução de 1930 até 1946.

Em 1920 na primeira fase do Brasil República diversos estados além do Rio de Janeiro iniciaram suas reformas educacionais e incluíram a Ginástica na escola. Além do mais, diversas escolas de Educação Física são criadas com o objetivo de formação militar. No entanto, é na segunda fase do Brasil República que a Educação Física começa a ganhar destaque nas discussões do Governo, logo após a criação do Ministério da Educação e Saúde criado em 1953.

Em 1937 se fez a primeira referência à Educação Física em textos federais na elaboração da Constituição, respaldando-a como prática educativa obrigatória e não mais como disciplina curricular, associada com ensino cívico e trabalhos manuais, em todas as escolas do país. Além disso, a Constituição citava o treinamento físico como maneira de preparar a juventude para a defesa da nação e cumprimentos de deveres relacionados à economia (BRASIL, 1997).

Os anos 30 (1930) foram marcados por mudanças na conjuntura do país que passava pela urbanização, pelo processo de industrialização e pelo estabelecimento do Estado Novo, período que também foi marcado pela criação das primeiras Instituições de Ensino Superior em Educação Física civis em São Paulo (1934) e no Rio de Janeiro (1939); um órgão central de direção no setor no antigo Ministério da Educação e Saúde, o Departamento de Educação Física (DEF) e se estabeleceram as bases de funcionamento para o Conselho Nacional de Desporto em 1941, conforme Junior e Simões (2011).

Diversos questionamentos e reflexões sobre a Educação Física fizeram parte do cenário nacional entre o final do Estado Novo (1937-1945) até a promulgação da Lei de Diretrizes e Base da Educação Nacional de 1961. Essa lei determinava que a Educação Física escolar fosse obrigatoriedade da educação primária e ensino médio. Assim, o esporte tomava cada vez mais espaço nas aulas, incorporando- o nas instituições tentando contrapor-se aos métodos da Ginástica (BRASIL, 1997).

Junior e Simões (2011) afirmam que um novo método de educar surgiu e estava pautado em contraposição ao discurso tradicional. A educação deveria ocorrer de forma integral, contemplando as instâncias física, intelectual e moral do homem. Para isso torna-se imprescindível o ensino da Educação Física nas escolas.

Novas tendências tomaram de conta das discussões sobre o cenário da escolar e a Educação Física passou a ser vinculada com a sociedade. As teorias críticas da educação foram responsáveis por mudanças nos objetivos, conteúdos, pressupostos pedagógicos de ensino e aprendizagem. Fatores como aspectos biológicos da formação, instâncias social, afetiva, psicológica e cognitiva passaram a ser eixos norteadores da componente curricular na escola. 
Com a mudança nos eixos norteadores, o importante passou a ser a formação de indivíduos que além de um físico desenvolvido tivesse também um físico que sustentasse a atividade intelectual. Com isso, os conteúdos foram diversificados, saindo da esfera de esportes e ginásticas e valorizando ideais pedagógicos mais humanos.

\section{As relações de gênero na Educação Física escolar}

Entender que o gênero se dá por meio de uma construção social não significa descartar que existem diferenças biológicas entre os sexos, mas sim que certas características são construídas. Essas diferenças biológicas são evidenciadas no ensino da Educação Física tradicional, voltada ao desempenho motor e técnico.

A prioridade de uma Educação Física Escolar voltada à coeducação no Brasil surge na década de 90 (1990). As questões de gênero aparecem como responsáveis na formação profissional e necessidades nas mudanças pedagógicas de ensino na Educação Física escolar.

Essas mudanças deveriam descontruir as relações de poder entre homens e mulheres nas práticas de desporto durante as aulas, binarismo de corpos e suas possibilidades de ação e potencialidade. Rever conceitos de que desportos são atividades masculinas e atividades rítmicas e expressivas são femininas também foi muito importante nesse processo, assim como afirmam Jesus e Devide (2006).

Em 1920 as aulas mistas foram criadas, na tentativa de igualar acesso entre homens e mulheres, porém a relação de superioridade do homem em relação à mulher ainda perpetua até os dias hoje, já que muitos professores ainda fazem uso de práticas que deixam transparecer estereótipos, que muitas vezes inconscientemente cobram coisas diferentes de meninos e meninas.

As aulas mistas segundo Jesus e Devide (2006), surgiram como forma de desconstruir padrões e estereótipos de gênero e como viabilização dos conteúdos para ambos os sexos, de forma igualitária. Acaba sendo complicado para os professores proporcionar aulas de forma mista com conteúdos que proporcionem uma prática de forma harmônica quando os alunos já estão acostumados a trabalharem de forma separada.

No início do ano letivo é comum que meninos e meninas, quando estimulados a fazerem aulas mistas, tenham sentimentos de recusa. Porém a problematização e a discussão sobre construções sociais de gênero, a participação de meninos e meninas em determinadas modalidades desportivas e a interação durante as aulas, pode diminuir os conflitos entre os sexos no contexto escolar segundo Jesus e Devide (2006).

Para que isso ocorra, a participação do docente torna-se fundamental no processo de intervenção pedagógica, quebrando estereótipos de homens e 
As relações de gênero na educação física escolar: um estudo de revisão bibliográfica

mulheres, minimizando a separação por sexo durante as aulas, corroborando para o desenvolvimento da solidariedade e promovendo respeito e tolerância entre ambos os sexos nas atividades motoras propostas.

Embora diversas transformações tenham ocorrido conforme o tempo e mesmo que haja um esforço para quebra de paradigmas no trabalho conjunto, a prática de separação por gênero na Educação Física escolar ainda é algo corriqueiro.

Sobre as aulas separadas por gênero, Jesus e Devide (2006) afirmam que nesse formato o docente tende a não dar atenção aos dois grupos simultaneamente, prejudicando o andamento e comprometendo a qualidade da aula. Além de que em escolas de espaço físico reduzido, meninos e meninas tem que esperar um pelo outro grupo para que possam utilizar o espaço, enquanto em contraposição em aulas mistas o espaço pode ser otimizado e ambos poderiam participar juntos no mesmo período de aula.

Contudo, Cruz e Palmeira (2009) afirmam que as aulas mistas possuem alguns entraves. Os professores da pesquisa feita pelos autores afirmam que meninos e meninas durante as aulas mistas têm uma boa relação, porém com algumas ressalvas. Quando o conteúdo das aulas especificamente é jogo, os meninos preferem não jogar com as meninas.

Para argumentar a separação das turmas por gênero, muitos profissionais utilizam diversas conclusões, em sua grande maioria reforçado por habilidades motoras ou valências físicas. Além do mais uma hegemonia no trabalho é considerada plausível para que haja separação.

Dentre os argumentos comuns mais utilizados a habilidade motora é bem citada e reforçada de que atrapalha o andamento das aulas. Porém esses argumentos têm raízes culturais identificadas por Abreu (1992) apud Jesus e Devide (2006), quando a mesma observou que irmãos e irmãs tendem a ter uma educação diferenciada.

Sendo assim, essa educação diferenciada propicia que os meninos tenham um tempo mais livre para as brincadeiras, vivenciando diversas atividades que ajudam na aquisição de habilidades e do repertório motor, enquanto meninas desde cedo são ensinadas para os afazeres domésticos, tendo pouco tempo para brincadeiras e que as mesmas vivenciam bem mais tarde atividades já na Educação Física escolar.

Na perspectiva docente analisada por Silva et al (2015) sobre a separação dos alunos nas aulas, afirma-se que esse fato se dá por meio de critérios que dizem respeito à agilidade, velocidade e força física. Os docentes consideram que esta divisão é algo "natural" logo que homens possuem o nível de força superior ao das mulheres e além do mais são mais ágeis. As aulas separadas por sexo não é apenas um modo de separar meninos e meninas, mas também de agradar ambos e fazer "fluir" uma "boa aula", pois meninas geralmente não gostam de conteúdos que os meninos gostam.

Segundo Silva et al (2015) sobre a pesquisa de Uchoga e Altmann (2010), revela-se que o conflito nas aulas mistas e a justificativa para a separação se dá 
por meio da argumentação de que meninas não conseguem acompanhar o ritmo dos meninos nas performances esportivas e que durante os jogos, meninos se empenhavam muito mais que as meninas e as mesmas não se importavam com a participação ativa durante a partida com tanto que vencesse, além do mais as mesmas pareciam reconhecer que eram desfavorecidas frente a força masculina, ou seja, as mesmas também eram responsáveis por perpetuar estereótipos de gênero.

Reforços de que a força corporal indica superioridade entre homens e mulheres foram sustentados durante muito tempo e a característica do formato da bacia indicava um destino natural da mulher à maternidade assim como afirma Meyer (2004) apud Jesus e Devide (2006).

Sobre força corporal, Weineck (2003) afirma que meninos e meninas pouco diferem entre si quanto ao nível de força muscular e sistema hormonal até o início da puberdade. Um menino antes de atingir a puberdade possui nível de testosterona muito baixo em relação à um homem adulto. Portanto, argumentos que sustentem os níveis de força principalmente no início da vida escolar (Ensino Fundamental -primeiros ciclos) para a separação nas aulas é equivocado, observando as afirmações e estudos do autor acima referenciado.

Segundo Sousa e Altmann (1999) no espaço educacional nós somos classificados por nossas características como idade, sexo, habilidade motora, entre outros, o que causa um emaranhado de exclusões vivido tanto por meninos como por meninas, o que se evidencia mais ainda nas aulas de Educação Física.

Então não se pode afirmar que as meninas são excluídas somente por serem do sexo feminino, mas por serem consideradas mais fracas e menos habilidosas por seus colegas ou por elas mesmas e outras colegas. Portanto, as relações entre meninos e meninas se constitui de forma hierarquizada nas aulas.

Sousa e Altmann (1999) ainda dizem que diferenças biológicas entre meninos e meninas servem para fortalecer ideias e conceitos estereotipados de gênero e mesmo ao longo dos anos o discurso permanece firme, pois a Educação Física ainda está atrelada à sua história e à biologia. E essa história mostra que as diferenças biológicas entre os sexos se ocultam em relações de poder marcadas pela dominação masculina.

Mesmo com uma nova forma de ensino focada no desenvolvimento integral do aluno e com a defesa das aulas mistas reforçada pelos Parâmetros Curriculares Nacionais, o símbolo da mulher dotada de fragilidade, emoção e fraquezas e do homem dotado de força, ainda é comum. |E os espaços físicos, conteúdos de ensino e técnicas do corpo permanecem sobre o domínio masculino.

Em um estudo realizado por Silva, Gomes e Goellner (2008) percebeu-se que as relações entre meninos e meninas eram vistas de forma diferente no contexto das aulas de Educação Física. Enquanto $50 \%$ das meninas percepcionavam que existiam más relações durante as aulas, $79 \%$ dos meninos percepcionavam boas relações e os $21 \%$ dos meninos que que percepcionavam más relações mostravam preferência por 
As relações de gênero na educação física escolar: um estudo de revisão bibliográfica

aulas que não fossem feitas de forma mista. Tratando-se das meninas que afirmam as más relações, descrevem que nos momentos de participação mista e inclusive durante os jogos, os meninos pouco davam oportunidade para que elas participassem.

Nota-se nas descrições dos resultados do estudo realizado por Silva, Gomes e Goellner (2008) que nas situações de jogo durante as aulas de Educação Física a partir de relatos dos próprios alunos, as mulheres são vistas sempre como mais fracas e como ameaça à equipe. Durante essas situações, as meninas relataram que quando há erro por parte delas os meninos chamam atenção das mesmas e é evidenciada a superioridade de um em relação ao outro. É como se os meninos fossem o tempo inteiro responsáveis por comandar os jogos e a presença de meninas dentro da competição fosse vista por eles como uma ameaça, elas terem a bola significa que o êxito está em risco. Elas ainda declaram desagrado em relação às atitudes dos colegas, que não as respeitam, promovendo um ambiente vazio e longe da realidade de igualdade requerida.

Sobre os conteúdos relacionados à Educação Física escolar e a atuação na divisão da turma em estudo realizado por Altmann Ayuob e Amaral (2011) apud Matos (2016), comprovou-se estar no discurso de alguns professores que durante a prática esportiva e jogos coletivos meninos mostram-se mais habilidosos que as meninas, e que grande parte delas preferem não fazer tais práticas para permanecerem arrumadas. Porém no decorrer do estudo os autores perceberam que essa concepção é tida como estereotipada conforme conceitos pré-estabelecidos entre masculino e feminino, pois nem todos os meninos gostam de práticas esportivas e algumas meninas também sabem e gostam de jogar.

Na participação de meninos e meninas em diversos conteúdos como jogos, brincadeiras, ginásticas e demais práticas corporais, a forma distinta com que ambos participam chama atenção, como observa Uchoga e Altmann (2015).

Em seus estudos observados em duas escolas, as práticas efetivas e não efetivas eram um dos propósitos do estudo. Sobre a participação não efetiva grande parte se deu por conta das meninas. Muitas não concluíram o objetivo da aula, e mesmo as que participavam tentavam de alguma forma se esquivar para não participar do andamento da aula que tinha como conteúdo basquetebol. Já os meninos, recebiam a bola com mais frequência tendo uma participação efetiva maior e desenvolviam habilidades de posicionamento no campo de jogo.

Uma outra observação a respeito da participação não efetiva nos estudos de Uchoga e Altmann (2015) foi durante as aulas que envolviam esportes coletivos como conteúdo. Em um jogo de queimada com objetivo de melhorar o arremesso e passe dos discentes e que tinha como regra o número de passes mínimos antes de arremessar a bola para o adversário, notou-se que os meninos tinham mais oportunidades no jogo. A turma foi composta por oito meninos e 26 meninas.

No dia do jogo, 22 meninas estavam presentes. As equipes foram divididas pela professora e tinha quatro meninos em cada equipe. O mais curioso é que no decorrer do jogo, os meninos ficavam à frente do campo para defender a bola e obtê- 
la, em seguida passavam a bola entre algumas meninas e no momento de arremessar voltavam a tomá-la para arremessar.

Os meninos então tentaram queimar alguém 60 vezes enquanto as meninas tentaram queimar alguém 28 vezes. Levando em consideração o número de integrantes e a relação entre a quantidade de ambos no jogo, cada menino arremessou em média sete vezes, enquanto as meninas arremessaram uma ou duas vezes cada. $E$ isso não se dá ao fato de que os meninos arremessem melhor do que as meninas, mas sim que elas acreditam que eles são melhores e eles também acreditam nisso e por isso pediam a posse de bola durante o jogo.

Sobre os arremessos realizados durante o jogo pelas meninas, grande maioria foi executado por Joana, que apresentava grande nível de força e habilidade percebidas durante a partida, após a mesma queimar um dos meninos. Após isso sua participação tornou-se mais efetiva e Joana recebeu mais bolas tanto dos meninos quando das meninas.

Interligado ao fato citado anteriormente, Uchoga e Altmann (2015) afirmam que pesquisas relacionadas a sociologia do esporte, com recorte nas teorias feministas, demonstram que a prática de atividades físicas, podem contribuir para o "empoderamento" feminino, tanto no campo físico como social. Além do mais através dessas atividades as mulheres podem desenvolver fisicalidade, controle de seu próprio corpo e experiências através do poder corporal.

Ao fim do estudo de Uchoga e Altmann (2015) constatou-se que não eram somente os conteúdos diferentes que interferiam nas relações de gênero na Educação Física escolar, mas também outras categorias que atuavam em conjunto com esses. Fatores como a confiança nas próprias habilidades, capacidade de arriscar-se em novas aprendizagens corporais, mediavam a forma com que meninos e meninas se relacionavam no momento da aula. Quanto a esses fatores, os meninos possuem uma visão mais positiva dos mesmos, o que propiciava um maior envolvimento nas aulas e permitiam que eles se arriscassem mais também.

Esse maior envolvimento nas atividades, faz com que meninos e meninas tenham desenvolvimento de habilidades distantes. Independente dos conteúdos eles se arriscavam mais, o que proporcionava a vivência de movimentos mais complexos, aprimorando habilidades corporais ligadas à força, ao equilíbrio, enquanto elas desenvolviam habilidades relacionadas à liderança e à organização, afirmam Uchoga e Altmann (2015).

Segundo Daolio apud Silva (2015) a Educação Física escolar deve contemplar todas as formas de cultura corporal do movimento, seguindo os blocos de conteúdos pertencentes à matriz curricular (jogos, esportes, lutas e ginásticas / atividades rítmicas e expressivas / conhecimento sobre o corpo). Portanto, ela deve focar não na performance e nem o rendimento esportivo do aluno, mas sim nos elementos da cultura corporal do movimento sistematizados e reconstruídos pelos alunos. 


\section{Considerações Finais}

Por muito tempo atividades corporais que demandam força, agilidade, velocidade, entre outros, estavam diretamente ligadas à prática masculina devido a construções sociais que viam o corpo feminino como dotado de fragilidade, distante do que as práticas físicas contemplam. Embora alguns tabus já tenham sido quebrados, a ideia de que mulheres não podem ou não devem realizar certas atividades ainda perpetua em algumas escolas e no conceito de alguns alunos e professores.

Analisar as relações de gênero na Educação Física escolar em turmas mistas é de grande importância para a melhoria e reflexão sobre a prática pedagógica. É importante salientar que a Educação Física faz parte da construção da corporeidade e identidade dos alunos e a mesma deve proporcionar aos alunos um ambiente livre de preconceitos, de prática saudável e faz parte da construção da corporeidade e identidade dos alunos.

Sobre as resultantes desse trabalho e após uma vasta revisão bibliográfica os objetivos geral e específicos foram respondidos. A evolução histórica da Educação Física mostra que foi constituída a partir de uma base puramente biológica que até hoje deixa resquícios de segregação de meninas nas aulas práticas e que embora os Parâmetros Curriculares Nacionais orientem aulas mistas e objetive a formação integral do indivíduo, a inclusão ainda caminha de forma lenta.

Sobre as relações de gênero durante as aulas de Educação Física podemos concluir que na maioria das vezes é marcada pela exclusão, falta de confiança por parte das meninas nelas mesmas, dificuldade de arriscar-se em novas práticas e que as relações de poder ainda se tornam mais evidentes quando tem esportes de contato como conteúdo.

Quando se trata de fatores que levam a divisão da turma por gênero, evidenciouse que o mais citado é o biológico. Sabe-se que as diferenças biológicas entre meninos e meninas existem, porém também existem diferenças sociais, culturais e políticas construídas historicamente.

\section{Referências}

ALTMANN, Helena. Educação Física Escolar: relações de gênero em jogo. São Paulo: Cortez Editora, 2015 (166 pp) - (Coleção Educação e Saúde - v. 11).

BRITO, Leandro; SANTOS, Mônica. Masculinidades na Educação Física Escolar: um estudo sobre os processos de inclusão/exclusão. Revista Brasileira Educação Física e Esporte: São Paulo, 2013. 
BRASIL. Secretaria de Educação Fundamental. Parâmetros Curriculares Nacionais $\left(5^{\mathrm{a}}\right.$ à $8^{\mathrm{a}}$ série): Educação Física/ Secretaria de Educação Fundamental - Brasília: MEC/SEF, 1998.

BRASIL. Secretaria de Educação Fundamental. Parâmetros Curriculares Nacionais ( $1^{\mathrm{a}}$ à $4^{\mathrm{a}}$ série): Educação Física/ Secretaria de Educação Fundamental - Brasília: MEC/SEF, 1997.

CASTELLANI FILHO, Lino. Educação Física no Brasil: A história que não se conta. Papirus: Campinas, 2016.

CURY, Rubiana Lopes; BASTOS, Flávia da Cunha. A Mulher no Contexto Político Brasileiro. OJM: Sarapuí, 2015.

CRUZ, Marlon Messias.; PALMEIRA, Fernanda Caroline. Construção da Identidade de Gênero na Educação Física Escolar. Motriz: Rio Claro, v.15 n.1, jan./mar. 2009, p. 116-131.

DEVIDE, F. P. et al. Estudos de Gênero na Educação Física Brasileira. Motriz, Rio Claro, v.17 n.1 p.93-103, jan./mar. 2011.

DORNELLES, Priscila. Distintos destinos? A separação entre meninos e meninas na Educação Física escolar na perspectiva de gênero. Dissertação (Mestrado em Educação) UFRS: Porto Alegre, 2007.

FREIXO, Manuel João Vaz. Metodologia cientifica - Coleção: epistemologia e sociedade. $4^{\circ}$ Ed., INSTITUTO PIAGET, 2012.

GERHARDT, Tatiana Engel; SILVEIRA, Denise Tolfo (Org.). Métodos de pesquisa. Porto Alegre: Editora da UFRGS, 2009.

GIL, Antônio Carlos. Métodos e Técnicas da Pesquisa Social. 6 a ed. São Paulo: Editora Atlas, 2008.

GOELLNER, Silvana. Gênero e esporte na historiografia brasileira: balanços e potencialidade. Revista Tempo, vol. 19, Junho de 2013, p. 45 a 52. 
GOMES, Paula; SILVA, Paula; QUEIROS, Paula. Equidade na Educação. Educação Física e Desporto na Escola. Associação Portuguesa. A Mulher e o Desporto: Lisboa, 2000.

HAERTEL, Bianca. A temática de gênero nas aulas de Educação Física do Ensino Médio: Pesquisa e Intervenção em escolas da cidade de São Carlos*. In: III Colóquio de Pesquisa Qualitativa em Motricidade Humana: o lazer em uma perspectiva latinoamericana, 2007, São Carlos. Anais... São Carlos: SPQMH DEFMH/UFSCar, 2007, p.99-115.

JESUS, Mauro Louzada de; DEVIDE, Fabiano Pries. Educação física escolar, coeducação e gênero: mapeando representações de discentes. Movimento, vol. 12, núm. 3, setembro-dezembro, 2006, p. 123-140

JESUS, Jaqueline Gomes. Orientações sobre Identidade de Gênero: Conceitos e Termos. $2^{a}$ edição, Brasília, 2012.

JUNIOR, Nestor. TASSONI, Elvira. A Educação Física, o docente e a escola: concepções e práticas pedagógicas. Revista Brasileira Educação Física e Esporte: São Paulo, 2013 Jul-Set, p. 463-483.

JUNIOR, Góis Edivaldo; SIMÕES, José Luís. História da Educação Física no Brasil. Universitária UFPE: Pernambuco, 2011.

LOURO, Guacira Lopes. Gênero e Sexualidade: Pedagogias Contemporâneas. Proposições, v. 19, n. 2 (56) - mai/ago, 2008, p. 17 - 23.

MATOS, N. da R. et al. Discussão de Gênero nas aulas de Educação Física: uma revisão sistemática. Motrivivência, v.28, n.47, maio/2016, p. 261-277.

MERIDA, Marcos. Educação Física Escolar: História e Cultura. Revista Mackenzie de Educação Física e Esporte.: supplement, Vol.9, fev., 2010, p.40-48

MORAES, Lourenza Lopes. Gênero, sexo: construção na Educação Física escolar. Belo Horizonte, 2011, 23 p. (Trabalho de Conclusão de Curso apresentado à Escola de Educação Física, Fisioterapia e Terapia Ocupacional, UFMG, para obtenção do título de Licenciado em Educação Física).

SANTANA, Anabela. Mulher Mantenedora/ Homem Chefe de Família. Itabaiana: GEPIADDE, Ano 4, Volume 8 | jul-dez de 2010.

SILVA, Paula.; GOMES, Paula Botelho; GOELNNER, Silvana. As relações de gênero do espaço da Educação Física. Revista Portuguesa de Ciências e Desporto, Porto: Universidade do Porto, 2008, p. 396-405. 
SILVA, Kelli et al. Gênero e Educação Física Escolar: Tensões e Implicações Pedagógicas. Colloquium Vitae. 2015, Vol. 7 Issue 1, p53-59.

SOARES, Everton Rocha. Educação Física no Brasil: da origem até os dias atuais. Edeportes.com, Revista Digital: Buenos Aires, junho de 2012.

SOUSA, Eustáquia. ALTMANN, Helena. Meninos e meninas: Expectativas corporais e implicações na Educação Física Escolar. Cadernos Cedes, ano XIX, n 48, Agosto, 1999.

SOUZA, Girlene; SANTOS, Anacleto; DIAS, Viviane. Metodologia da Pesquisa Científica: a construção do conhecimento e do pensamento científico no processo de aprendizagem. Animal: Porto Alegre, 2013

UCHOGA, Liana Aparecida; ALTMANN, Helena. Educação Física escolar e relações de gênero: diferentes modos de participar e arriscar-se nos conteúdos de aula. Colégio Brasileiro de Ciências do Esporte, Elsevier: Campinas, 2015.

WEINECK, Jürgen. Treinamento Ideal: instruções técnicas sobre o desempenho fisiológico, incluindo considerações específicas de treinamento infantil e juvenil. Manole: Barueri, $1^{\mathrm{a}}$ edição, 2003.

Recebido em maio de 2020.

Aprovado para publicação em abril de 2021. 